ORIGINAL ARTICLE

\title{
Bronchoscopy in Nigerian Clinical Practice: A Survey of Medical Doctors' Perception, Use and Associated Challenges
}

\author{
Adekunle Olatayo Adeoti ${ }^{*}$, Olufemi Olumuyiwa Desalu ${ }^{2}$, Joseph Olusesan \\ Fadare $^{1}$, Wemimo Alaofin ${ }^{2}$, Cajetan Chigozie Onyedum ${ }^{3}$
}

OPEN ACCESS

Citation: Adekunle Olatayo Adeoti ${ }^{1 *}$, Olufemi Olumuyiwa Desalu², Joseph Olusesan Fadare ${ }^{1}$, Wemimo Alaofin ${ }^{2}$, Cajetan Chigozie

Onyedum ${ }^{3}$.Bronchoscopy in Nigerian Clinical Practice: A Survey of Medical

Doctors' Perception, Use and Associated Challenges. Ethiop J Health Sci 2017;27(4):331.

doi:http://dx.doi.org/10.4314/ejhs.v27i4.4

Received: February 16, 2016

Accepted February 24, 2017

Published: July 1, 2017

Copyright: () 2017Adeoti A.O.et al. This is an open access article distributed under the terms of the Creative Commons Attribution License, which permits unrestricted use, distribution, and reproduction in any medium, provided the original author and source are credited.

Funding: Nil

Competing Interests: The authors

declare that this manuscript was approved

by all authors in its form and that no

competing interest exists.

Affiliation and Correspondence:

${ }^{1}$ Department of Medicine, Ekiti State

University Teaching Hospital, Ado-

Ekiti, Nigeria

${ }^{2}$ Department of Medicine, University of Ilorin Teaching Hospital, Ilorin,

Nigeria

${ }^{3}$ Department of Medicine, University

of Nigeria Nsukka Teaching

Hospital, Enugu, Nigeria

*Email:kadeoti2002@yahoo.com

\section{ABSTRACT}

BACKGROUND: Bronchoscopy is a vital diagnostic and therapeutic procedure in pulmonological practice. The aim of this study was to determine the perception, use and challenges encountered by Nigerian medical doctors involved in this procedure.

MATERIALS AND METHODS: A cross-sectional study was conducted among 250 medical doctors recruited from three major tertiary institutions in Nigeria between September 2013 and June 2014. A semi-structured questionnaire was self-administered to adult physicians, paediatricians, and surgeons as well as their trainees to obtain their perception, use and associated challenges in the use of bronchoscopy in clinical practice.

RESULTS: The majority (91.6\%) of the respondents perceived bronchoscopy as a beneficial procedure to respiratory medicine. However, 59.2\% of them were not aware of the low mortality rate associated with this procedure. The commonest indications for bronchoscopic use were foreign body aspiration (88.8\%) and management of lung tumors (75.6\%). Only 21 (8.4\%) of the respondents had received formal training in bronchoscopy. Very few procedures (1-5 cases per month) were performed. The respondents identified the lack of formal training in the art of bronchoscopy as the foremost challenge facing its practice in Nigeria. In addition, availability of bronchoscopes, level of awareness, knowledge of the procedure among medical doctors and the cost of the procedure were the challenges faced by the medical doctors.

CONCLUSION: There is an urgent need to equip training centers with modern bronchoscopic facilities. In addition,well-structured bronchoscopic training programme is imperative to enhance the trainees' proficiency for the furtherance of bronchoscopic practice. KEYWORDS: Bronchoscopy, Nigeria, Respiratory medicine, Interventional pulmonology, Training 


\section{INTRODUCTION}

Ever since the first bronchoscopy was performed by Gustav Killian in 1897, this endoscopic pulmonological procedure has evolved into an indispensible interventional tool in the management of several respiratory diseases $(1,2)$. Bronchoscopy is a vital diagnostic and therapeutic procedure performed essentially by respiratory physicians, thoracic surgeons and paediatrians skilled in this art. Despite its rapidly advancing and dynamic nature in most developed countries, it is still at the rudimentary stage in most developing countries like Nigeria.

Nigeria is a country burdened with both communicable and non-communicable respiratory diseases like tuberculosis, pneumonia, bronchial asthma and chronic obstructive pulmonary disease $^{(3)}$. Although respiratory diseases constitute about $10 \%$ of the total medical admissions in Nigeria, there is a deficit in the human and infrastructural resources necessary to facilitate accurate diagnosis and treatment, especially in complicated cases requiring the use of a bronchoscope(4)(5). The register of the Nigerian Thoracic Society shows that 76 registered members cater for the entire population at 1 per 2.3 million individuals which is a far cry from what obtains in other countries(6). For instance, the Graduate Medical Education National Advisory Committee (GMENAC) and the Goodman et al reports recommended an average respiratory physician (Pulmonologist) to population ratio of 1.5 per 100,000 and 1.4 per 100,000 respectively $(5,7)$. Despite this shortage in Pulmonologists in the country, there is a clustering of the available ones in the urban centers, with the rural dwellers having relatively low accessibility to pulmonologists.

In Nigeria, functional bronchoscopy suite is available in very few centers with its use mostly dominated by the thoracic surgeons, even though both fibreoptic and rigid bronchoscopes are available in such facilities despite the former being in the purview of the physicians(6). This has a significant effect on the level of exposure and training of bronchoscopists who should be equipped with the necessary skills required for performing this procedure. Notwithstanding the regional variability in bronchoscopy training programmes, the consensus is focused on standardized skill acquisition and knowledgebased competency assessment for the trainees. Most centers adopt the multimodal training approach vis-a-vis specific skill acquisition through lectures, web-based learning, use of simulators and hands-on supervision $(8,9)$.

Surveys of bronchologic practice have been conducted in several countries but none, to the best of our knowledge, in Nigeria(10-13). With the paucity of data on the subject of bronchoscopic practice and training structure in Nigeria, there was a need to conduct this study with the objective of determining medical doctors' perceptions, use and the challenges facing bronchoscopic practice in Nigeria.

\section{MATERIALS AND METHODS}

Study design and population: A cross-sectional study was conducted among medical doctors in three tertiary institutions in Nigeria. The study was conducted between September 2013 and June 2014. All cadres of medical doctors in the three core specialties (Internal medicine, Surgery and Paediatrics) where patients often require bronchoscopic procedure were recruited for the study.

Study area:The study was carried out in three selected teaching hospitals in three of the six geopolitical zones in Nigeria. Nigeria is the most populous black nation with an estimated population of over 160 million. It is located in West Africa and divided into six geopolitical zones, namely: North-East (NE), North-Central (NC), North-West (NW), South-West (SW), South-East (SE), and South-South (SS). One tertiary institution was selected from three (NC, $\mathrm{SW}, \mathrm{SE}$ ) of the six geopolitical zones based on the population of medical doctors in the center and availability of training programme in the three core specialties. The population of doctors in the three departments in those institutions was 489 (SW 102, SE 185 and NC 202) with the ratio of the eligible doctors in these institutions being 1 to 1.8 to 2 . 
Sample size: The minimum sample size was calculated using the Cochran's formula(14): $\mathrm{N}=\mathrm{z}^{2}$ $\mathrm{pq} / \mathrm{d}^{2}$ where $\mathrm{N}$ is the sample size, $\mathrm{p}$ is $50 \%, \mathrm{z}$ is standard normal deviation set at 1.96 corresponding to the $95 \%$ confidence interval and $\mathrm{d}$ is the degree of accuracy desired usually set at $0.05 . \mathrm{q}$ is however equal to $1-\mathrm{p}$. Correction for finite population as the target population is less than 50,000. Hence, the calculated sample size was 216. To give allowance for non-response and increase the power of the study, the final sample size was increased to 300 .

Data collection:A pretested, semi-structured questionnaire was used as a survey instrument. A pilot survey was conducted among 10 medical doctors during an annual meeting of the Nigerian Thoracic Society held at Ile-Ife, Nigeria, between $26^{\text {th }}$ and $29^{\text {th }}$ of November 2013. This was done to ensure that the questions were properly worded and well understood by respondents. Subsequently, the investigators supervised the filling of the self-administered questionnaire with required information on participants' sociodemographic characteristics, bronchoscopy use, perception of the Medical Doctors and the challenges facing bronchoscopic practice in their respective centers. Eligibility for this study depended on being a qualified medical doctor, practicing or training in the three core specialties in those selected institutions. A proportionate allocation of the questionnaires to the different institutions (ratio of 1:1.8:2) was done, and they were administered by stratified random technique to ensure every strata of the profession is represented as random sampleswere taken from each stratum. A table of random samples using the list of eligible doctors for the study in the various institutions was used in the selection process, and the questionnaires were administered during their departmental meetings.

Data analysis:Thedata were analysed using statistical software SPSS version 20 (SPSS Inc., Chicago, IL, USA). Categorical variables were presented in frequencies and percentages while continuous variables were expressed as mean \pm standard deviation. Multivariate analysis was performed to determine the strength of association between bronchoscopic practice and the factors associated with its use.

Ethical consideration:Informed consent form was signed by all participants. Ethical approval was obtained from the Ekiti State University Teaching Hospitalethical research committee.

\section{RESULTS}

Two hundred and fifty of the 300 administered questionnaires were completed and returned by the respondents (response rate of $83.3 \%$ ). Males accounted for $73.3 \%$ of the respondents. The specialists in the three major specialties involved in bronchoscopy, and their trainees participated in this study (Table 1). The ratio of the specialists to trainees was 1:2.4, 1:2.7 and 1:7.8 amongst the physicians, paediatricians and surgeons respectively. The majority of the respondents $(91.6 \%)$ perceived bronchoscopy as very important to respiratory medicine practice. However, more than half were unaware of the mortality rate following this procedure. Aspiration of foreign body $(88.8 \%)$ and management of lung tumour $(75.6 \%)$ were the two major perceived useful indications for bronchoscopy by the respondents while chronic obstructive pulmonary disease (COPD) (25.6\%), and bronchial asthma $(25.2 \%)$ were assumed to have fewer benefits from this procedure by the respondents (Table 2).

DOI: http://dx.doi.org/10.4314/ejhs.v27i4.4 
E640p J Health Sci.

Vol. 27, No. 4

July 2017

Table 1: General profile of Respondents

\begin{tabular}{ll}
\hline Characteristics & Frequency \\
\hline Age (Years) & $\mathrm{N}(\%)$ \\
$<30$ & $48(17.2)$ \\
$30-39$ & $157(62.8)$ \\
$40-49$ & $41(16.4)$ \\
$>50$ & $9(3.6)$ \\
& \\
Sex & \\
Male & $183(73.3)$ \\
Female & $67(26.7)$ \\
& \\
Specialty & \\
Adult Physician & $35(14.0)$ \\
Surgeon & $11(4.5)$ \\
Paediatrician & $9(3.7)$ \\
Adult Physician-in-training & $84(33.5)$ \\
Surgeon-in-training & $86(34.3)$ \\
Paediatrician-in-training & $25(9.9)$ \\
Number of years post graduation & $7(1 \mathrm{QR} 5-10)$ \\
\hline
\end{tabular}

Table 2: Perception of Medical Doctors about Bronchoscopy

\begin{tabular}{|c|c|c|c|c|}
\hline \multicolumn{2}{|c|}{ Questions on Medical Doctors' Perception } & \multicolumn{3}{|l|}{ Response } \\
\hline \multirow[t]{2}{*}{ i. } & Do you think bronchoscopy is useful in & Yes $(\%)$ & No $(\%)$ & I don't know (\%) \\
\hline & $\begin{array}{l}\text { the diagnosis and treatment of } \\
\text { respiratory conditions? }\end{array}$ & $229(91.6)$ & $10(4.0)$ & $11(4.4)$ \\
\hline ii. & $\begin{array}{l}\text { Mortality rate is very high following } \\
\text { bronchoscopy? }\end{array}$ & $17(6.8)$ & $85(34.0)$ & $148(59.2)$ \\
\hline iii. & $\begin{array}{l}\text { The following conditions may benefit } \\
\text { from bronchoscopy }\end{array}$ & $\mathrm{N}(\%)$ & & \\
\hline & a. Foreign body aspiration & $222(88.8)$ & & \\
\hline & b. Lung tumour & $189(75.6)$ & & \\
\hline & c. Sarcoidosis & $113(45.2)$ & & \\
\hline & d. Pulmonary tuberculosis & $104(41.6)$ & & \\
\hline & e. COPD & $64(25.6)$ & & \\
\hline & f. Bronchial asthma & $63(25.2)$ & & \\
\hline
\end{tabular}

About three quarter of the respondents had functioning bronchoscopes in their centers. However, less than half $(40.0 \%)$ of the respondents observed this procedure. A minority of the respondents were actively involved in bronchoscopy (8.8\%) which almost equals the percentage of respondents who had formal bronchoscopy training (8.4\%). Furthermore, in centers where bronchoscope is available, very few cases were performed. About two third of the respondents stated that patients who required bronchoscopic procedures were managed in their center while about a third of the respondents avowed that such patients were referred to other centers within and outside the country. More than half of the medical doctors $(51.2 \%)$ were either

DOI: http://dx.doi.org/10.4314/ejhs.v27i4.4 
not aware of the type of bronchoscope (vis-a-vis have one in their center (Table 3 ).

rigid or flexible) available in their center or do not

Table 3: Factors affecting Bronchoscopic practice among Medical Doctors

\begin{tabular}{|c|c|c|}
\hline \multicolumn{2}{|c|}{ Bronchoscopic practice } & $\mathbf{N}(\%)$ \\
\hline i. & Have you ever observed bronchoscopy? & $100(40)$ \\
\hline \multirow[t]{2}{*}{ ii. } & Have you had any formal training in & $21(8.4)$ \\
\hline & bronchoscopy? & $181(72.4)$ \\
\hline iii. & $\begin{array}{l}\text { Do you have facility for bronchoscopy in } \\
\text { your center? }\end{array}$ & $22(8.8)$ \\
\hline iv. & $\begin{array}{l}\text { Are you involved in bronchoscopy in your } \\
\text { center? }\end{array}$ & $39(81.3)$ \\
\hline \multirow[t]{5}{*}{ v. } & How many bronchoscopies do you do per & $7(14.6)$ \\
\hline & month? & $2(4.2)$ \\
\hline & $1-5$ cases per month & \\
\hline & $6-10$ cases per month & $30(12.0)$ \\
\hline & $10-15$ cases per month & $48(19.2)$ \\
\hline \multirow[t]{6}{*}{ vi. } & What type of bronchoscope do you use in & $44(17.6)$ \\
\hline & your center? & $128(51.2)$ \\
\hline & Flexible & \\
\hline & Rigid & $80(36.7)$ \\
\hline & Both & $131(60.1)$ \\
\hline & None / I don't know & $7(3.2)$ \\
\hline \multirow[t]{4}{*}{ vii. } & $\begin{array}{l}\text { Where do you manage patients who require } \\
\text { bronchoscopy? }\end{array}$ & \\
\hline & Refer & \\
\hline & Manage in your center & \\
\hline & Others & \\
\hline
\end{tabular}

The major determinants of bronchoscopic practice were the ready availability of bronchoscope and access to bronchoscopy training as stated by the respondents in the study (Table 4). The respondents identified the need for training in bronchoscopy as the foremost challenge facing itspractice in Nigeria. In addition, availability of bronchoscopes, level of awareness and knowledge of the procedure among medical doctors and the cost of the procedure constituted the other challenges faced by the respondents (Figure 1).

Table 4: Determinants of Use of Bronchoscope among Medical Doctors

\begin{tabular}{lll}
\hline Associated factors & $\mathrm{r}^{2}$ & $\mathrm{p}$ - value \\
\hline 1. Age & 0.05 & 0.46 \\
2. Sex & 0.09 & 0.19 \\
3. Specialty & -0.09 & 0.19 \\
4. Years of practice post-qualification & -0.01 & 0.83 \\
5. Formal bronchoscopy training & 0.44 & $<0.001^{*}$ \\
6. Facility for bronchoscopy in your center & 0.19 & $<0.001^{*}$ \\
7. Number of bronchoscopic procedure per month & 0.04 & 0.78 \\
8. Mortality rate following bronchoscopy & 0.12 & 0.07 \\
9. How useful is bronchoscopy in the diagnosis and & 0.08 & 0.20 \\
& & \\
\hline
\end{tabular}

DOI: http://dx.doi.org/10.4314/ejhs.v27i4.4 


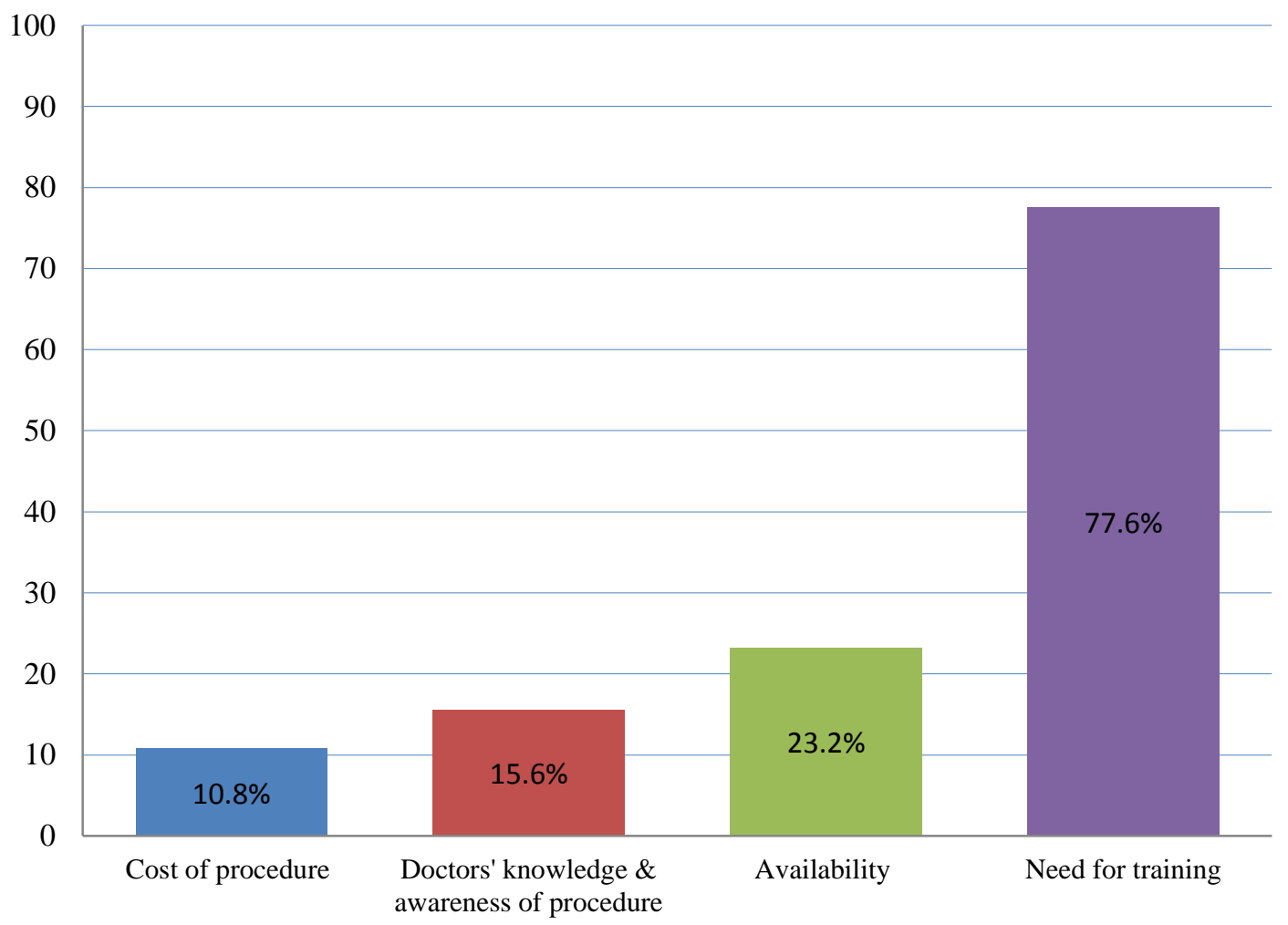

Figure 1: Identified challenges facing bronchoscopic practice in Nigeria

\section{DISCUSSION}

The study shows respondents' limited perception of the scope of bronchoscopic practice and the inchoate use of bronchoscope in our environment. In addition, the major challenge confronting bronchoscopic practice is the inaccessibility to formal training programme and lack of bronchoscopes for training.

Awareness among respondents on bronchoscopic practice seems to be more in the management of lung tumour and foreign body aspiration but less reported in COPD and bronchial asthma. The potentially achievable cure following early detection and accurate staging of lung cancers(15) as well as the urgency in addressing a life-threatening foreign body aspiration(16) could have made these conventional indications for bronchoscopy to be topmost among the respondents' indications for bronchoscopy. However, novel use of bronchoscopic lung volume reduction for COPD and bronchial thermoplasty for asthma were less recognized indications for bronchoscopy among the respondents. This could be due to novelty in use of these management options, their level of awareness and the rudimentary stage of bronchologic practice in Nigeria $(2,17)$.

Notwithstanding the very low attributable mortality rate from bronchoscopy $(18)$, several of the respondents were not aware of this fact. This dearth of knowledge could probably be the result of the limited exposure to bronchoscopy as the respondents reported few cases that might have presented at terminal stage for the procedure coupled with the ill-equipped facilities. In spite of the individual experiences in this skilled procedure, medical doctors are expected to be familiar with international best practices and expected outcomes of procedure.

Clinical observership in medical practice is the early step towards mastery of any procedure. This preceptorship is often introduced at the elementary stage of medical training(19).

DOI: http://dx.doi.org/10.4314/ejhs.v27i4.4 
Surprisingly, however, less than half of the respondents observed bronchoscopy. This could be due to the few cases performed in those centers where the medical doctors may not have had the opportunity to witness such a procedure during their rotations. Furthermore, the interest of resident doctors in respiratory medicine is said to be determined by their level of exposure and experience during the period of rotation in the unit. Consequently, the provision of modern facilities like bronchoscope by the training institutions served as an impetus in the choice of this subspecialty of internal medicine(20).

Contrary to the minimum numbers-based recommendations of expected bronchoscopies to be performed by specialists (50 per year), the majority $(81.3 \%)$ of those respondents performed between 1 and 5 per month (12 to 60 per year). Likewise, $28 \%$ and $49 \%$ of the specialists of the American and Australasian bronchoscopists, respectively, performed fewer than the recommended bronchoscopies per year $(21,22)$. This brings to the fore the need to augment conventional training in bronchoscopy using real patients under supervision with the use of simulators $(21,23)$.

The paradigm shift in the approach to training of bronchoscopists from the conventional supervision using real patients has been reviewed by several thoracic societies with the consensus of a multimodal methodology which entitles the use of simulators and web-based lectures in addition to the conventional style $(9,10,21)$. A major challenge facing bronchoscopic practice as highlighted by the respondents is the need for proper training. The adoption of a multimodal approach will help in meeting the recommended exposure to this procedure with the aim of improving competence and patient safety.

In addition, furnishing the current facilities with the modern technology to elevate them to the state of the art status in bronchologic practice will make the available centers perform optimally. Subsequently, more centers could be equipped as more trainees become fellows. This will address the challenge related to availability of bronchoscopy as a second major challenge facing its practice in Nigeria.
In conclusion, there is an urgent need to review the policies towards encouraging the provision of well-equipped bronchoscopy suite in hospitals and for capacity building in this important skill to improve respiratory care in the country. Finally, a review of postgraduate training curriculum to emphasize and enforce the acquisition of this skill and establishment of guidelines for bronchoscopic practice to help harmonize the training of bronchoscopists in the country is imperative.

\section{REFERENCES}

1. Ouellette DR. The safety of bronchoscopy in a pulmonary fellowship program. CHEST Journal. 2006;130(4):1185-90.

2. Plekker D, Koegelenberg CFN, Bolliger CT, editors. Different techniques of bronchoscopy. Plymouth: European Respiratory Society; 2010.

3. Umoh VA, Otu A, Okpa H, Effa E. The pattern of respiratory disease morbidity and mortality in a tertiary hospital in southerneastern Nigeria. Pulm Med. 2013;2013:581973.

4. Desalu OO, Ojo OO, Busari OA, Fadeyi A. Pattern of respiratory diseases seen among adults in an emergency room in a resourcepoor nation health facility. Pan African Medical Journal. 2011;9(1):24.

5. Goodman DC, Fisher ES, Bubolz TA, Mohr JE, Poage JF, Wennberg JE. Benchmarking the us physician workforce: An alternative to needs-based or demand-based planning. JAMA. 1996;276(22):1811-7.

6. Obaseki D, Adeniyi B, Kolawole T, Onyedum C, Erhabor G. Gaps in Capacity for Respiratory Care in Developing Countries. Nigeria as a Case Study. Annals of the American Thoracic Society. 2015;12(4):591-8.

7. Jacoby I. Geographic distribution of physician manpower: the GMENAC (Graduate Medical Education National Advisory Committee) legacy. J Rural Health. 1991;7(4 Suppl):42736.

8. Hardavella G, George J. Interventional bronchoscopy in the management of thoracic

DOI: http://dx.doi.org/10.4314/ejhs.v27i4.4 
malignancy. Breathe (Sheff). 2015 Sep;11(3):202-12.

9. Ernst A, Wahidi MM, Read CA, Buckley JD, Addrizzo-Harris DJ, Shah PL, et al. Adult bronchoscopy training: Current state and suggestions for the future: chest expert panel report. Chest. 2015;148(2):321-32.

10. Asano F, Aoe M, Ohsaki Y, Okada Y, Sasada $\mathrm{S}$, Sato $\mathrm{S}$, et al. Bronchoscopic practice in Japan: a survey by the Japan Society for Respiratory Endoscopy in 2010. Respirology. 2013;18(2):284-90.

11. 11. Hautmann H, Hetzel J, Eberhardt R, Stanzel F, Wagner M, Schneider A, et al. Cross-Sectional Survey on Bronchoscopy in Germany-The Current Status of Clinical Practice. Pneumologie. 2016;70(02):110-6.

12. Honeybourne D, Neumann CS. An audit of bronchoscopy practice in the United Kingdom: a survey of adherence to national guidelines. Thorax. 1997 Aug;52(8):709-13.

13. Prakash UB, Offord KP, Stubbs SE. Bronchoscopy in North America: the ACCP survey. Chest. 1991 Dec;100(6):1668-75.

14. Cochran WG. Sampling techniques-3. 1977.

15. Sharma D, Newman TG, Aronow WS. Lung cancer screening: history, current perspectives, and future directions. Arch Med Sci. 2015 Oct 12;11(5):1033-43.

16. Dikensoy O, Usalan C, Filiz A. Foreign body aspiration: clinical utility of flexible bronchoscopy. Postgrad Med J. 2002 Jul;78(921):399-403.

17. Castro M, Musani AI, Mayse ML, Shargill NS. Bronchial thermoplasty: a novel technique in the treatment of severe asthma. Ther Adv Respir Dis. 2010 Apr;4(2):101-16.

18. Stahl DL, Richard KM, Papadimos TJ. Complications of bronchoscopy: A concise synopsis. Int J Crit Illn Inj Sci. 2015 JulSep;5(3):189-95.

19. Kumar P. Clinical observership: A desirable adjunct to preclinical training. Australas Med J. 2011;4(6):294-9.

20. Desalu OO, Onyedum C, Adeoti A, Ozoh O, Sogaolu O, Gunduri L, et al. Factors affecting interest in respiratory medicine as a subspecialty of choice: survey of internal medicine residents in Nigeria. The Nigerian postgraduate medical journal. 2013;20(4):291-8.

21. Ost D, DE ROSIERS A, Britt EJ, Fein AM, LESSER ML, MEHTA AC. Assessment of a bronchoscopy simulator. American journal of respiratory and critical care medicine. 2001;164(12):2248-55.

22. Dabscheck EJ, Hew M, Irving L, Steinfort D. Bronchoscopic training and practice in australia and New Zealand is inconsistent with published society guidelines. Journal of bronchology \& interventional pulmonology. 2014;21(2):117-22.

23. Moorthy K, Smith S, Brown T, Bann S, Darzi A. Evaluation of virtual reality bronchoscopy as a learning and assessment tool. Respiration. 2003;70(2):195-9. 